\title{
Delivery of surgical care in a district general hospital without high dependency unit facilities
}

\author{
R P Coggins
}

\begin{abstract}
Background-Many hospitals lack the facilities for high dependency care, and patients requiring this level of care are nursed on the surgical ward. The aim of this study was to assess the extent of this problem in a district general hospital, looking at the impact of providing high dependency unit (HDU) care at ward level.
\end{abstract}

Methods-A 28 bed surgical ward was studied for 39 consecutive days. Patients were assessed as being either appropriately placed (routine) or inappropriately placed (HDU). Nursing interventions and observations over each 24 hour period were recorded for the most dependent patient in each group.

Results-Data were collected for a total of 1092 bed days. Median bed occupancy was 22 patients/day (78\%). Inappropriately placed HDU patients accounted for 55 bed days (5\%, mean 1.4 patients/day). These patients required more nursing intervention than routine patients.

HDU patients received more observations during a 24 hour period than routine patients (mean 11.3 and 4.2 respectively, $p<0.005)$. The number of observations recorded for a routine patient in a 24 hour period fell when a HDU patient was nursed concurrently on the ward (mean $5.1 / 24$ hours, falling to $3.8 / 24$ hours in the presence of an HDU patient, $\mathbf{p}<0.02$ ).

Conclusions-HDU patients require more intensive nursing care than routine surgical patients, and the nursing of HDU patients on the ward adversely affects the quantity of care available for less dependent patients. High dependency care should therefore be provided in dedicated units.

HDU is an essential facility for all surgical patients, including those who require intensive nursing, and the routine surgical patient whose nursing is compromised by the failure to provide comprehensive postoperative care. (Postgrad Med f 2000;76:223-226)

Birch Hill Hospital, Rochdale, UK

Correspondence to: Mr R P Coggins, ICRF Genetic Epidemiology Laboratory, Ashley Wing St James' Hospital, Beckett Street, Leeds LS9 7TF, UK (e-mail:

RonCoggins@aol.com)

Submitted 16 December 1998

Accepted 13 August 1999 is that surgery should not be performed on physiologically compromised patients without adequate facilities for postoperative care. ${ }^{3}$ Fur- that should be available in all hospitals where surgery is performed. ${ }^{12}$ The recommendation of the report of the National Confidential Enquiry into Perioperative Deaths for 1992/93
Keywords: graduated patient care; postoperative care; dependency thermore, the Royal College of Anaesthetists and the Royal College of Surgeons of England see the HDU as forming an essential tier in a system of graduated patient care, where patients are placed according to clinical need in units providing intensive, high dependency, postoperative, convalescent, or long stay care. ${ }^{4}$ However, there is an apparent shortage of HDUs currently in the UK, with HDU facilities available in only $20 \%$ of hospitals. ${ }^{35-7}$ What constitutes a HDU? In 1991 the Association of Anaesthetists of Great Britain and Ireland defined the HDU as being an area for patients who require more intensive observation, treatment, and monitoring than can be provided on a general ward. Patients needing invasive monitoring could be appropriately placed on a HDU, but such a unit would not have facilities for mechanical ventilation. ${ }^{8}$ It has been suggested that HDU care should be considered for patients undergoing aortic surgery, major colorectal or upper gastrointestinal surgery, or after any emergency laparotomy. It should also be considered for patients with closed head, thoracic, or abdominal trauma. ${ }^{2} 10$

Where are dependent patients nursed in hospitals that lack recognised HDU facilities? There is evidence that some patients end up on intensive care units, where they potentially block beds for more appropriate patients. ${ }^{11}{ }^{12}$ Many of these patients will be nursed on a general surgical ward, where nursing ratios are insufficient to deliver the necessary care, as well as look after other patients nursed on that ward at the same time.

The perceived benefits of HDU care are difficult to quantify in practice, requiring prospective, controlled study that is difficult to justify on ethical grounds. The aim of this study was to look at the nursing care delivered to ward nursed surgical patients in a district general hospital without a designated HDU, looking particularly at the implications for care of routine patients.

\section{Methods}

A 28 bed surgical ward in a district general hospital was studied prospectively for 39 consecutive days from 1 July to 8 August 1997. A day was defined as being the 24 hour period from midnight to midnight. Two surgeons admit routinely to this ward, with a workload including vascular, upper and lower gastrointestinal and breast cases, as well as emergency surgical cases. Patients were assessed by the author based upon their clinical dependence. Patients who had undergone aortic surgery, oesophagectomy, gastrectomy, major colonic resection, who had been admitted with 
Table 1 Requirement for nursing intervention for $H D U$ and routine patients

\begin{tabular}{lclc}
\hline & $\begin{array}{l}\text { No (\%) routine } \\
(n=39)\end{array}$ & $\begin{array}{l}\text { No (\%) HDU } \\
(n=27)\end{array}$ & $p$ Value \\
\hline Medications & $38(97.4)$ & $26(96.3)$ & 1.0 \\
IV treatments & $23(62.2)$ & $23(85.2)$ & 0.053 \\
IV infusions & $32(82.1)$ & $27(100)$ & 0.04 \\
PCA & $4(10.3)$ & $15(55.6)$ & 0.0001 \\
Dressings & $23(59)$ & $26(96.3)$ & 0.0005 \\
Toiletting & $29(74.4)$ & $27(100)$ & 0.004 \\
Catheter care & $13(13.3)$ & $27(100)$ & $<0.0001$ \\
Feeding & $27(69.2)$ & $22(81.5)$ & 0.39 \\
Position & $25(64.1)$ & $25(92.6)$ & 0.009 \\
Fluid balance & $37(94.9)$ & $27(100)$ & 0.51 \\
CVP & 0 & $13(48.2)$ & $<0.0001$ \\
Hygiene & $26(66.7)$ & $26(96.3)$ & 0.005 \\
SaO $_{2}$ & $20(51.3)$ & $25(92.6)$ & 0.0004 \\
\hline
\end{tabular}

^Statistical analysis using Fisher's exact test; significance assumed where $\mathrm{p}<0.05$.

$\mathrm{CVP}=$ central venous pressure; $\mathrm{IV}=$ intravenous; $\mathrm{PCA}=$ patient controlled analgesia; $\mathrm{SaO}_{2}=$ oxygen saturation.

severe pancreatitis or sepsis, or who had cardiac or respiratory complications after surgery were considered suitable for HDU care. Other patients were categorised according to the concept of graduated patient care as being postoperative or convalescent. General throughput for the study period was obtained from ward records. Inpatients were assigned to two groups: those who had been appropriately placed on the ward (routine) and those who were inappropriately placed (HDU). The most dependent patient in each group was identified, and as a representative of the group as a whole, nursing interventions and observations for this patient over each 24 hour period were recorded. Data were obtained regarding requirement for medications, intravenous medications, intravenous infusions, need for patient controlled analgesia or epidural analgesia, dressings, toiletting or stoma care, catheter care, feeding or nutritional support, positional changes, fluid balance, central venous pressure measurement or central venous catheter care, general hygiene, or oxygen saturation measurement. In addition, the actual number of observations (temperature, pulse, blood pressure) and oxygen saturation measurements charted in the preceding 24 hours were documented. Routine patients were divided into two subgroups on the basis of whether there was or was not an HDU patient on the ward on that particular study day. The number of recorded observations for each group was then compared.

STATISTICAL ANALYSIS

Statistical analysis was performed using a commercial statistical software package (Statistica 4.5, Statsoft Inc 1993). Throughput results are presented as bed days. Averages are presented as the median with range in parentheses unless stated otherwise. Comparison of required nursing intervention in the two groups (HDU and routine) was performed using Fisher's exact test. Differences in the numbers of recorded observations and oxygen saturation were compared using the Mann-Whitney U test. Statistical significance was assumed where $\mathrm{p}<0.05$.

\section{Results}

Data were collected for a total of 1092 bed days. Median daily bed occupancy was 22 patients (14-28). A total of 856 out of 1092 beds were occupied at the beginning of a shift, with a bed occupancy of $78.4 \%$.

During the study period, there was a total of 88 elective admissions ( $8.1 \%$ of total throughput, median 2/day, range 0-9), and 71 emergency admissions (6.5\%, median 2 /day, range $0-5)$. Eighty five patients were taken to theatre $(7.8 \%$, median $1 /$ day, range $0-10)$. Fifty five patients were judged to be suitable for high dependency care $(5.0 \%$, median 1 /day, mean 1.4/day, range 0-4). Patients requiring high dependency care were present on the ward for 28 out of the 39 days. Postoperative patients accounted for 590 bed days ( $54 \%$, mean 15.1, range 8-22). Convalescent patients occupied 171 beds $(15.7 \%$, mean 4.4, range $0-13)$, while preoperative patients (self caring patients waiting $>24$ hours for surgery) occupied 32 beds $(2.9 \%$, mean 0.8 , range $0-4)$.

Nursing interventions required for routine and HDU patients are shown in table 1 . Statistical significance is seen for requirement for intravenous infusions $(\mathrm{p}=0.04)$, patient controlled analgesia $(p=0.0001)$, dressings $(p=0.0005)$, toiletting $(p=0.004)$, catheter care $(p<0.0001)$, positional changes $(p=0.009)$, central venous pressure measurement $(p<0.0001)$, general hygiene $(p=0.005)$, and oxygen saturation measurement $(\mathrm{p}=0.0004)$.

Observations (temperature, pulse blood pressure), and oxygen saturation measurements recorded and charted during a 24 hour period are shown in table 2 . Values are given for HDU and routine patients. HDU patients have more observations $(p=0.0004)$ and oxygen saturation measurements $(p<0.0001)$ charted than routine patients. There is a significant reduction in the number of observations charted for routine patients when a HDU patient is nursed concurrently on the ward $(p=0.0126)$. This difference is not seen for

Table 2 Recorded observations/24 hours for HDU and routine patients

\begin{tabular}{llll}
\hline & $\begin{array}{l}\text { Mean (range)/ } \\
24 \text { hours HDU } \\
(n=28)\end{array}$ & $\begin{array}{l}\text { Mean (range)/ } \\
24 \text { hours routine } \\
(n=39)\end{array}$ & $p$ (U statistic)* \\
\hline Observations & $11.3(3-42)$ & $4.2(2-10)$ & $\begin{array}{l}0.0004 \\
(\mathrm{U}=285)\end{array}$ \\
& $\begin{array}{l}\text { Median }=4 \\
\mathrm{SaO}_{2}\end{array}$ & $\begin{array}{l}\text { Median }=4 \\
1.84(0-12)\end{array}$ & $\begin{array}{l}<0.0001 \\
(\mathrm{U}=161)\end{array}$ \\
\hline
\end{tabular}

* Statistical analysis using Mann-Whitney $\mathrm{U}$ test; significance assumed where $\mathrm{p}<0.05 . \mathrm{SaO}_{2}=$ oxygen saturation.

Table 3 Recorded observations/24 hours for routine patients nursed in the presence and absence of HDU patients

\begin{tabular}{llll}
\hline & $\begin{array}{l}\text { Mean (range)/ } \\
\text { 24 hours } \\
\text { HDU present } \\
(n=28)\end{array}$ & $\begin{array}{l}\text { Mean (range)/ } \\
\text { 24 hours No } \\
\text { HDU present } \\
(n=11)\end{array}$ & $p($ U statistic)* \\
\hline Observations & $3.8(2-6)$ & $5.1(2-10)$ & $0.0126(\mathrm{U}=87)$ \\
$\mathrm{SaO}_{2}$ & $\begin{array}{l}\text { Median }=4 \\
1.7(0-12)\end{array}$ & $\begin{array}{l}\text { Median }=4 \\
2.3(0-8)\end{array}$ & $0.57(\mathrm{U}=132)$
\end{tabular}

^Statistical analysis using Mann-Whitney U test; significance assumed where $\mathrm{p}<0.05 . \mathrm{SaO}_{2}=$ oxygen saturation. 
oxygen saturation measurements $(p=0.57)$ (table 3).

\section{Discussion}

Provision of postoperative care in the UK is, more than ever before, undergoing a period of scrutiny. The reports of the National Confidential Enquiry into Perioperative Deaths repeat the message that some surgical deaths could be avoided by provision of high dependency unit care, ${ }^{3}{ }^{13}$ while the Royal College of Anaesthetists and the Royal College of Surgeons of England have stated the need for structured, graduated postoperative care. ${ }^{4}$ In their vision of the future of surgical care, the HDU will be a step on the ladder in which surgical wards will look after "postoperative" patients only-that is, those patients who require intermittent clinical observations and therapeutic interventions more than twice daily by appropriately trained nurses. Less dependent patients will be nursed on a convalescent or hotel unit, where they will be self caring, and will need no clinical interventions other than those that can be provided by domiciliary support or a visit to the outpatient clinic.

The description of a district general hospital without facilities for HDU care is far from uncommon in the UK, and there is little evidence to suggest that this situation is changing. Development of such care strategies is hindered by cost implications, although the report of The Joint Working Party on graduated patient care describes a model, which it suggests would carry no additional financial burden. ${ }^{4}$ Furthermore, although accepted in principle, there is little hard evidence that provision of HDU care has a beneficial effect on outcome. To date the debate has focused on the possible benefits to patients requiring HDU care.$^{14}$ However, staying within the concept of graduated patient care, it must be asked whether less dependent patients suffer as a result of sharing their limited nursing resources with inappropriately placed HDU patients.

This paper describes activity in a busy general hospital, with a broad spectrum of cases passing through a surgical ward. This study demonstrates that patients suitable for HDU care are often nursed on the general ward, and on a daily basis at least one bed will be occupied by a patient who could be better served on a HDU. The observation that HDU patients occupied $5 \%$ of all beds is in keeping with data published previously. ${ }^{4}$ Similarly, the mix of postoperative and convalescent patients follows the pattern seen elsewhere. ${ }^{4}$

This study confirms that those patients thought suitable for HDU care are more dependent upon nursing expertise, time, and resources than other routine patients. Consideration of a wide range of nursing interventions shows that HDU patients require significantly more input than routine patients. The only exceptions to this are the need for medications and intravenous treatments, help with feeding and fluid balance (table 1). These data have been analysed only in terms of either needing or not needing a particular intervention. Observations and oxygen saturation measure-

\section{Learning points}

- Surgical patients require nursing care appropriate to their clinical need.

- Highly dependent surgical patients are often present on general surgical wards.

- High dependency patients can be nursed at ward level, but consequently affect the nursing resources available for less dependent patients.

- High dependency care should be provided in dedicated units, within a graduated system of patient care.

ments have been analysed quantitatively. It is significant that more observations and oxygen saturation measurements are charted for HDU patients than for routine patients (table 2), demonstrating that HDU patients require a greater proportion of their carer's time. This extra care is presumably given at the expense of less dependent patients. This study looked specifically at the pattern of charted observations for routine patients. The number of charted observations fell when a HDU patient was nursed on the ward, compared with when there were no HDU patients on the ward (table 3). This is also seen with recorded oxygen saturation measurements, although the small sample size prevents demonstration of statistical significance. It is concluded therefore that care can be provided for HDU patients at ward level, but only by reducing the time available for less dependent patients. Whether this has a measurable effect on outcome cannot be concluded from this study, but these data provide an interesting hypothesis for further investigation.

\section{Conclusions}

The failure to provide HDU facilities has implications for the management of general surgical wards. HDU patients occupy a substantial number of ward beds on a regular basis, and require a larger proportion of nursing time than routine postoperative patients. The nursing of HDU patients on the ward has an adverse effect on the quantity of care delivered to routine patients. Attempts to nurse both patient groups in the same unit results in suboptimal care, and may adversely affect outcome.

The HDU is an essential facility that must become a feature of all surgical units. All patients require high dependency facilities, both those who actually receive intensive nursing, and those routine surgical patients whose nursing is compromised by the failure to provide comprehensive facilities for postoperative care.

I would like to thank the nursing staff at Birch Hill Hospital for their valuable help in assessing the patients under their care.

\footnotetext{
1 Crosby DL, Rees GA. Provision of postoperative care in UK hospitals. Ann R Coll Surg Engl 1994;76:14-18.

2 Gamil M, Fanning A. The first 24 hours after surgery. A

study of complications after 2153 consecutive operations. Anaesthesia 1991;46:712-15.
} 
3 Campling EA, Devlin HB, Hoile RW, et al. The report of the National Confidential Enquiry into Perioperative Deaths,

4 Royal College of Anaesthetists and the Royal College of Surgeons of England. Report of the joint working party on graduated patient care. London: Royal College of Anaesthetists and the Royal College of Surgeons of England, January 1996

5 Metcalfe A, McPherson K. Study of provision of intensive care in England, 1993. London: Department of Health, January 1995.

6 Rennie M. Strengthening the case of high dependency care. British fournal of Intensive Care 1995:5:5.

Royal College of Anaesthetists. National ITU audit. London: Royal College of Anaesthetists, 1992/93.

8 Association of Anaesthetists of Great Britain and Ireland. The high dependency unit - acute care in the future. London: Association of Anaesthetists of Great Britain and Ireland, 1991.
9 Crosby DL, Rees GA, Gill J. The role of the high dependency unit in postoperative care: an update. Ann $R$ Coll Surg Engl 1990:72:309-12.

10 Nehra D, Crumplin MK, Valijan A, et al. Evolving role of intensive and high dependency care. Ann R Coll Surg Engl 1994;76:9-13.

11 Nelson JB Jr. The role of an ITU in a community hospital. A ten year review with observations on utilisation past, present and future. Arch Surg 1985;120:123-6.

12 Knaus WA, Wagner DP, Draper EA. The range of intensive care services today. $\mathcal{F} A M A 1981 ; 246: 2711-16$.

13 Campling EA, Devlin HB, Hoile RW, et al. The report of the National Confidential Enquiry into Perioperative Deaths 1991/1992. London: 1993.

14 Coggins R, de Cossart L. Improving postoperative care: the role of the surgeon in the high dependency unit. Ann R Coll Surg Engl 1996:78:163-7.

\section{IMAGES IN MEDICINE}

A 45 year old woman presented with shortness of breath and ankle swelling. She smoked 20 cigarettes a day and had recently completed an alcohol detoxification programme. A diagnosis of cardiac failure was made, with alcoholic cardiomyopathy a possible cause. However an echocardiogram was performed which revealed a more unusual cause for her cardiac failure. This showed a mass pressing against the left atrium (see fig 1). Histological examination revealed a squamous bronchial carcinoma. The tumour was inoperable because of metastatic spread. She underwent palliative radiotherapy and died four months after the initial diagnosis.

HELEN GENTLES

Conquest Hospital, Hastings Correspondence to: Dr Gentles, 40 Whichelo Place, Brighton BN2 2XF

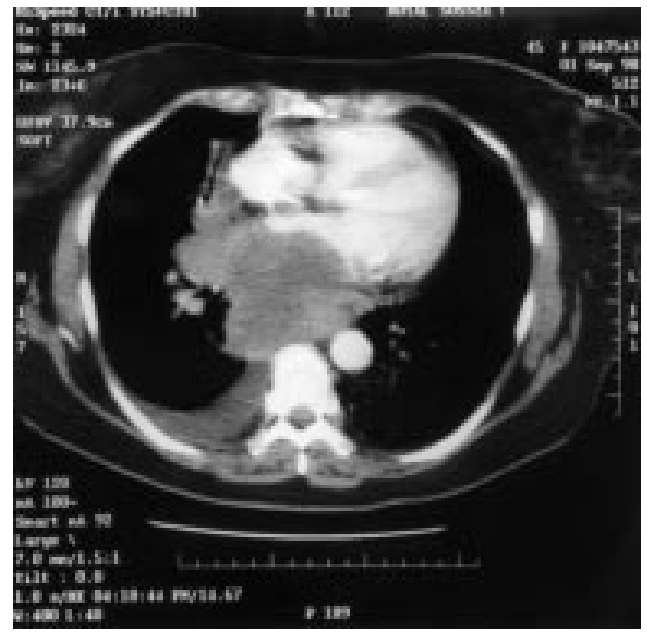

Figure 1 Computed tomogram of a transverse view of the thorax showing a large mediastinal mass compressing the left atrium. 